\title{
EXPERIMENTAL STUDIES ON STRESS CONCENTRATION FACTORS FOR PARTIALLY OVERLAPPED CIRCULAR HOLLOW SECTION K-JOINTS
}

\author{
C.K. Lee ${ }^{*}$, S.P. Chiew, S.T. Lie, T. Sopha and T.B.N. Nguyen \\ School of Civil and Environmental Engineering, Nanyang Technological University \\ 50, Nanyang Avenue, Singapore 639798 \\ *(Corresponding author: E-mail: ccklee@ntu.edu.sg)
}

Received: 14 May 2008; Revised: 9 July 2008; Accepted: 29 July 2008

\begin{abstract}
This paper describes the testing results of two full-scale partially overlapped circular hollow section (CHS) K-joints. The two specimens were designed in such a way that partially overlapping is inevitable in order to eliminate the eccentricity of the resulted joints. Experimental studies were carried out by applying static loadings at the end of the through braces of the joints. The stress distributions of the partially overlapped CHS K-joints tested under the three basic loading cases (axial (AX), in-plane (IPB) and out-of-plane bending (OPB)) and their combinations were carefully recorded during the test. For each specimen, experimental study was carried out to investigate the stress concentration factor (SCF) and the hot spot stress (HSS) distributions along the brace-chord intersections. The experimental results obtained show that even for a simple combination of AX and IPB loading cases, the maximum HSS could be located either on the brace side or the chord side of the joints. The SCFs obtained from the experimental studies are compared with the SCF formulae suggested by Efthymiou and Durkin [1] and those from finite element analyses. It is observed that Efthymiou's formulae may not be completely suitable for the design of partially overlapped CHS K-joints.
\end{abstract}

Keywords: Partially overlapped circular hollow section K-joint, stress concentration factor, hot spot stress, fatigue assessments

\section{INTRODUCTION}

Simple non-overlapped circular hollow section (CHS) K-joint is one of the most widely used connection types in offshore structures. However, due to the existence of a gap between the braces, under some geometrical configurations, eccentricity and unbalanced moment could be generated on the chord and this may lead to undesirable brittle responses of the joints (BOMEL [2]). Hence, in many design codes (Zhao et al. [3] and EC3 [4]), an upper limited is imposed on the eccentricity for non-overlapped K-joints. In practice, any eccentricity for a non-overlapped CHS K-joint could be eliminated by partially overlapping the braces. When compared with a non-overlapped K-joint, a partially overlapped CHS K-joint normally has a higher fabrication cost due to the more complex intersection profile. However, due to their optimized load transfer pattern and zero eccentricity property, partially overlapped CHS K-joints often offer a higher residual capacity and ultimate strength (Bouwkamp [5-6]). In a study carried out by Healy [7], it was found that in case the through brace was in tension, the capacity of partially overlapped joint was much better than when it was otherwise loaded. Dexter and Lee [8-9] examined numerically the effects of several geometrical parameters and the overlapping percentage on the behaviour of overlapped joints. It was founding that, in general, overlapping the braces has a beneficial effect on joint strength for the joints with relatively thick brace walls. Furthermore, it was also reported from Dexter et al. [10] that partially overlapped CHS K-joints are expected to have increased strength up to a certain amount of overlap and then decrease when the joint is completely overlapped. Besides strength enhancement, partially overlapped joint could also lead to more cost effective joint design. In a study carried out by Tizani et. al. [11], it is found that after considering both material and fabrication costs, the use of a partially overlapped joint could lead to the cheapest solution with the addition fabrication cost actually offset by avoiding the use of canned gap joint as an alternative. 
In the study of fatigue performance of partially overlapped CHS K-joints, works by Bouwkamp [5-6] found that the stress concentration factor (SCF) could be reduced by more than $30 \%$ when compared with the non-overlapped CHS K-joints having the same parameters and properties. Fessler et al. [12] also observed that the hot spot stress (HSS) of a partially overlapped CHS K-joint is $40 \%-45 \%$ less than a gap joint. Furthermore, having compared the results of overlapped and gapped CHS K-joints, Gibstein [13] concluded that fatigue strength improvements could be obtained by using a partially overlapped joint with same chord and brace diameter. So far, the most detailed work related to the SCF and the HSS distributions of this joint type was published by Efthymiou and Durkin [1]. Over 100 partially overlapped CHS K-joints were analyzed using finite element (FE) models for nine different load cases. Parametric equations were then developed for each load case and the results were experimentally verified by Dharmavasan and Seneviratne [14] using acrylic models. It was found that overlapping helps reduce the chord SCFs significantly.

Despite the above mentioned advantages of a partially overlapped K-joint, equations for the fatigue design of this type of joints are not commonly available in design code. Efthymiou and Durkin [1] had published some formulae but they were not adopted in the EC3 [4]. Furthermore, not many full scale testing results related to the SCF and the HSS values for partially overlapped CHS K-joints were reported (Lee et al. [15]). The main objective of this study is to investigate experimentally the SCF distribution around the brace-chord intersection for this type of joints. Static tests were conducted for two carefully designed full scale partially overlapped CHS K-joints. Basic (AX, IPB and $\mathrm{OPB}$ ) and combined loadings were applied to the joints and detailed measurements for the stresses induced along the joint intersection were made. A comparison between the experimental results obtained with Efthmiou's formulae [1] and those obtained from FE modeling are then carried out.

\section{SET UP OF THE TEST RIG AND THE LOADING SYSTEM}

The tests of the partially overlapped CHS K-joints were carried out using the "orange” rig (Figure 1) located in the Construction Technology Laboratory, School of Civil and Environmental Engineering, Nanyang Technological University. This test rig is designed for static and fatigue tests of hollow section joints under AX, IPB and OPB loads or combinations of them. The test rig has three actuators namely, Actuators 1, 2 and 3 (Figure 2) installed at one end of the rig which are able to apply cyclic loadings with adjustable frequency to the specimen along three mutually perpendicular axes. In this study, Actuators 1 and 2 which have a maximum capacity of $250 \mathrm{kN}$ were employed to apply AX and IPB loadings, respectively. Actuator 3 with a maximum capacity of $150 \mathrm{kN}$ was employed for the generation OPB loading. All three actuators can apply both tension and compression loadings and they can be operated individually or concurrently to create combined loading conditions.

\section{THE SPECIMENS TESTED}

In this study, two full scale partially overlapped CHS K-joints (Specimen I and Specimen II) were test. The typical test set up of the two specimens and their geometrical properties are shown in Figures 1 and 3. Each joint specimen comprises the chord, a through brace and an overlapping brace. The angles between the braces and the chord are equal to $45^{\circ}$ and $60^{\circ}$ for Specimens SI and Specimen SII, respectively. These two joints were fabricated using structural steel pipes compiled to the BS EN10210-S355 J2H standard. The joints were welded according to the AWS specifications [16]. Ultrasonic checking was conducted along all the welding paths to ensure that the welding at the intersections of the chord and braces was complete penetration groove weld with 
standard flat profile. In the set up of each specimen, both ends of the chord and the overlapping brace were welded onto the flat plates and bolted directly onto strong reaction panels of the rig. The end of the through brace was welded onto a flat plate and bolted directly onto the actuators (Figure 2). The physical dimensions and other important non-dimensional parameters of the specimens are listed in Table 1. The material properties of the sections obtained from standard coupon tests are summarized in Table 2. Note that the section sizes and configurations of these two specimens were carefully selected in such a way that if they are fabricated as non-overlapped joints with minimum gap spacing, the eccentricity of the resulted joints shall exceed the maximum limit imposed by the EC3 [4].

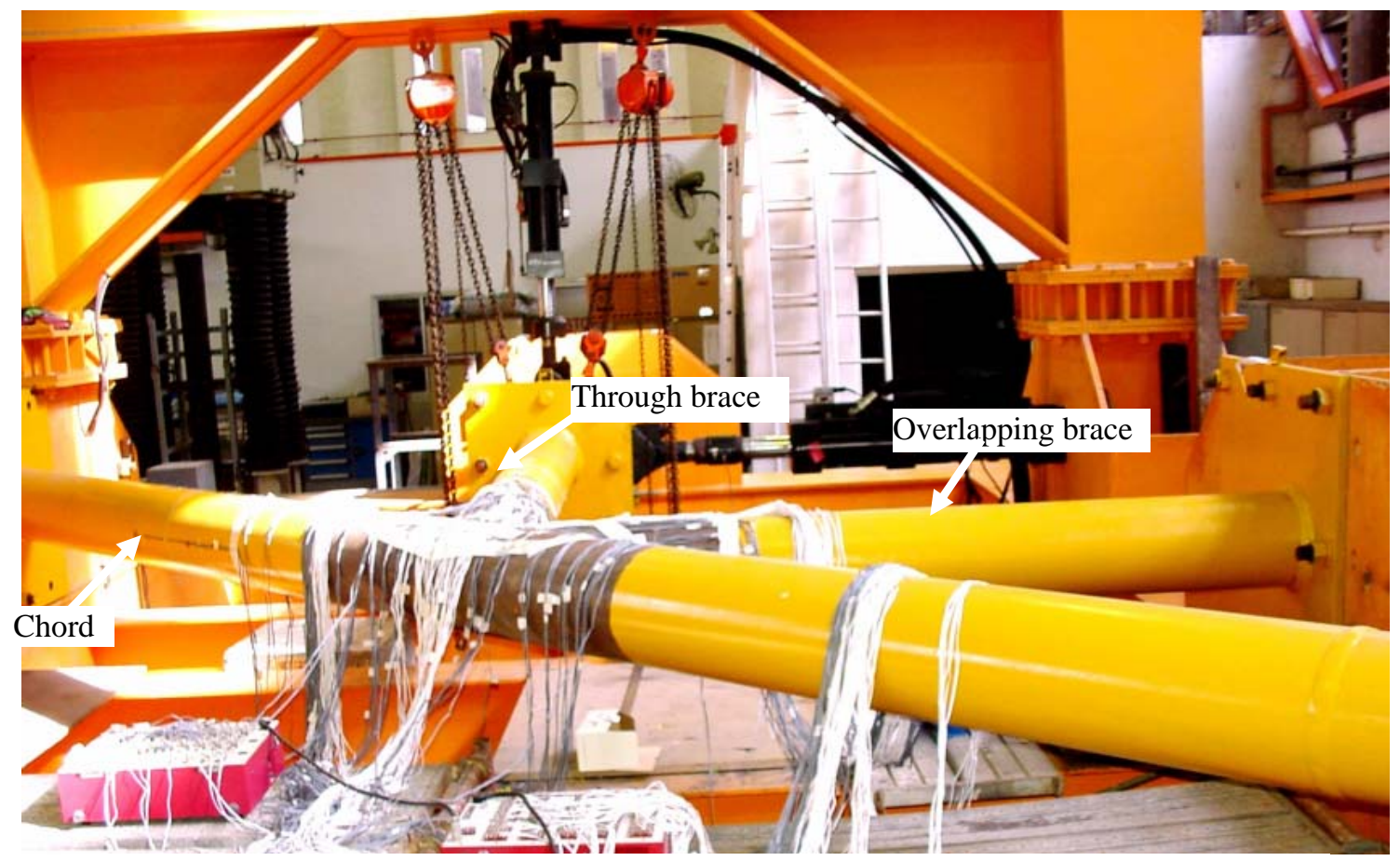

Figure 1. The "Orange” rig and the Partially Overlapped CHS K-Joint Specimen

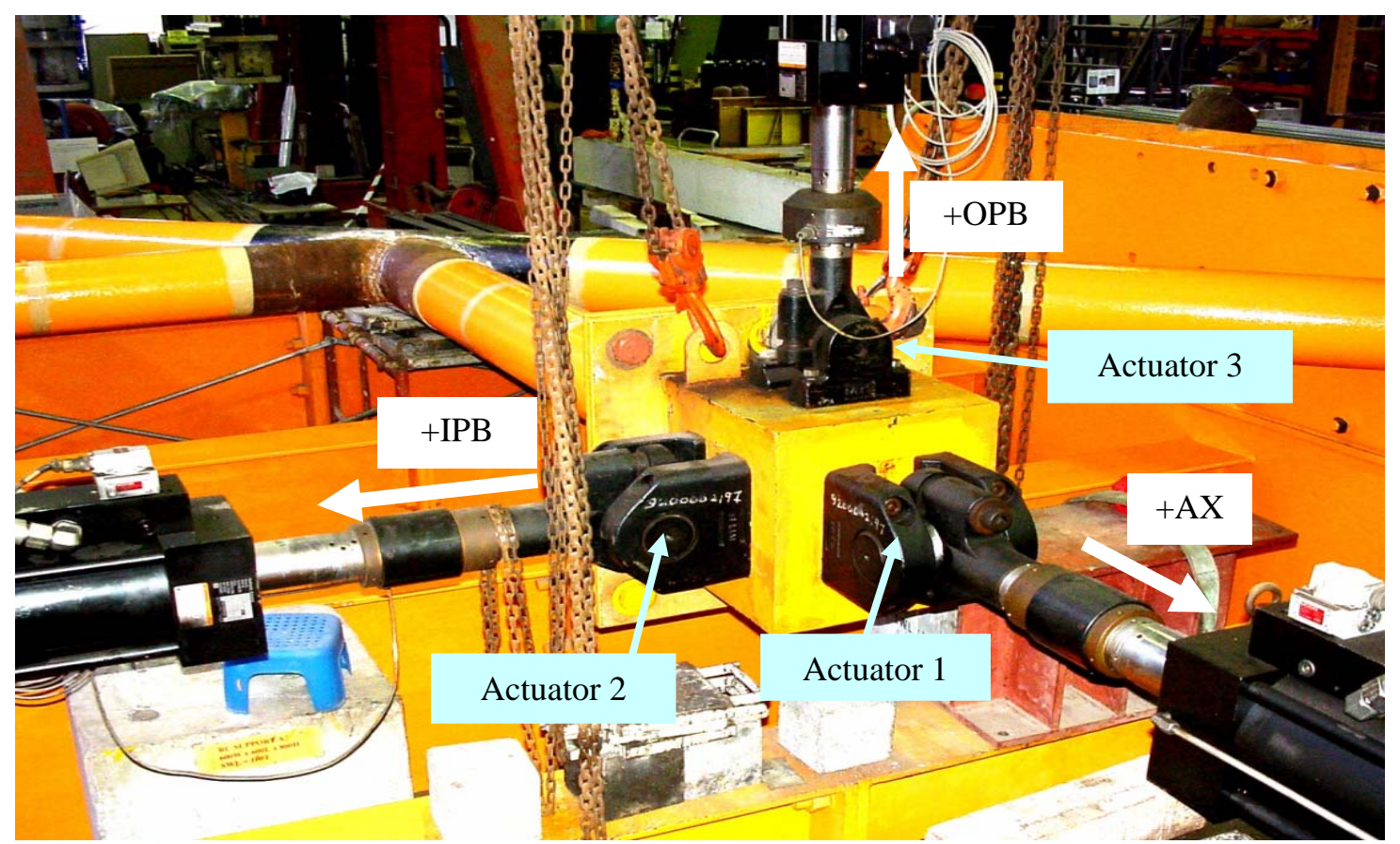

Figure 2. Actuators and Loading Directions 
Table 1. Dimension of Specimens

\begin{tabular}{|c|c|c|c|c|c|c|c|c|}
\hline Specimen & $D(\mathrm{~mm})$ & $T(\mathrm{~mm})$ & $d(\mathrm{~mm})$ & $t(\mathrm{~mm})$ & $\theta_{l}\left(^{\circ}\right)$ & $\theta_{2}\left(^{\circ}\right)$ & $O_{V}(\%)$ & $e(\mathrm{~mm})$ \\
\hline SI & 273 & 26 & 244.5 & 20.0 & 45 & 45 & 21 & 0 \\
\hline SII & 355.6 & 16 & 323.9 & 16 & 60 & 60 & 45.35 & 0 \\
\hline
\end{tabular}

(a) Physical Dimensions

\begin{tabular}{|c|c|c|c|c|}
\hline Specimen & $\alpha=2 L_{C} D$ & $\beta=d / D$ & $2 \gamma=D / T$ & $\tau=t / T$ \\
\hline SI & 42.789 & 0.895 & 10.50 & 0.769 \\
\hline SII & 27.146 & 0.91 & 22.22 & 1.00 \\
\hline
\end{tabular}

(b) Non-Dimensional Parameters

Table 2. Material Properties of the Specimens

\begin{tabular}{|c|c|c|c|c|}
\hline \multirow{2}{*}{ Specimen } & Member & $\begin{array}{c}\text { Yield strength } \\
\text { (MPa) }\end{array}$ & $\begin{array}{c}\text { Tensile strength } \\
\text { (MPa) }\end{array}$ & $\begin{array}{c}\text { Modulus } \\
\text { of Elasticity } \\
\text { (GPa) }\end{array}$ \\
\hline \multirow{2}{*}{ SI } & Chord & 403.9 & 553.6 & 207.5 \\
\hline \multirow{2}{*}{ SII } & Braces & 426.9 & 585.1 & 201.9 \\
\cline { 2 - 5 } & Chord & 428.17 & 526.00 & 204.21 \\
\cline { 2 - 5 } & Braces & 424.23 & 564.94 & 200.89 \\
\hline
\end{tabular}

\section{STRAIN AND STRESS MEASUREMENTS}

Since the main objective of this study is to investigate the HSS and the SCF distributions along the intersections of the tubular sections, extensive strain measurements were conducted by installation of strain gauge arrays at the joint. At the joint intersections, three curves, namely, Curves $\mathrm{A}, \mathrm{B}$ and $\mathrm{C}$ were identified (Figure 4). Curve $\mathrm{A}$ is the intersection between the through and the overlapping brace. Curves $\mathrm{B}$ and $\mathrm{C}$ are the intersections between the chord and the overlapping and the through braces, respectively. From Figure 4, it can be seen that for each side of the joint, these three curves meet at a junction point. Along these three curves, strain gauges were installed at locations near the weld toe of the chord and the braces to record the strain distributions. As from many past studies (Lee et al. [15, 17]), the quadratic extrapolation method (Zhao et al. [3]) is needed to obtain accurate strain measurements, three rows of strain gauges were installed at each measurement location along the line perpendicular to the weld toe at distances equal to $0.4 t, 1.0 t$ and $1.4 t$ ( $t$ is the thickness of member) from the weld toe (Figures 4 and 5). Three types of strain gauge arrangements were deployed in this study (Figure 5). At locations far way from the junction point and the saddle and crown of the intersections, a single perpendicular strain gauge arrangement is used. At the saddle and crown of the intersections, an arrangement of a pair of strain gauges arranged in the perpendicular and the parallel directions to the weld toe was adopted. Finally, in order to capture the complex strain pattern, rosettes were deployed at regions close to the junction point. Besides along the intersection curves, eight strain gauges were also installed at the two cross-sections along the through brace to detect any secondary bending moment caused by load eccentricity and joint flexibility (Figure 6). During the test, all strain gauges were connected to four TML ASW-50 switchboxes and a TML TDS-801 data logger. The data logger was then connected to a personal computer where special software for monitoring, collecting and processing of the testing data was installed. 


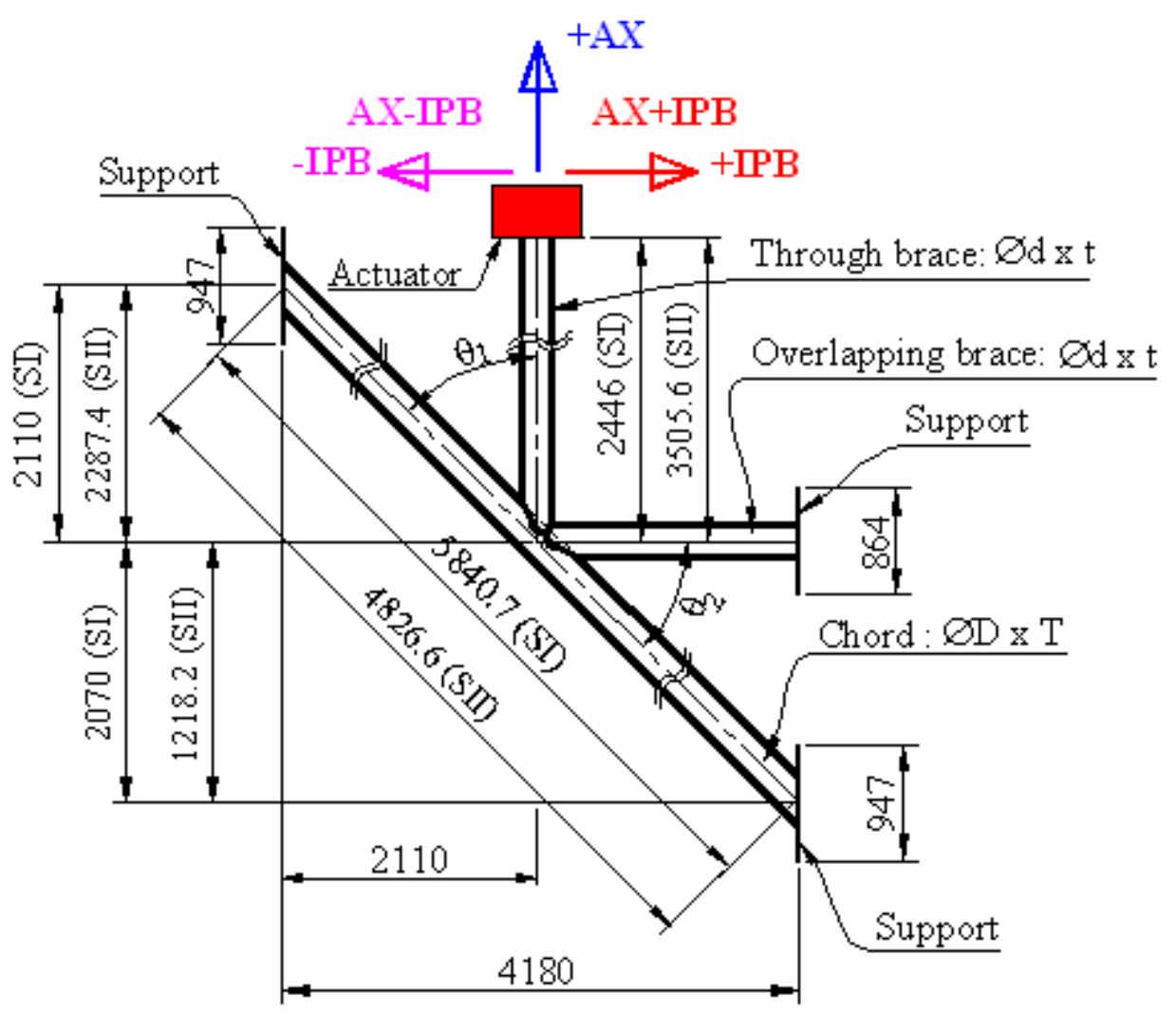

Figure 3. Dimensions and Configuration of the Specimens

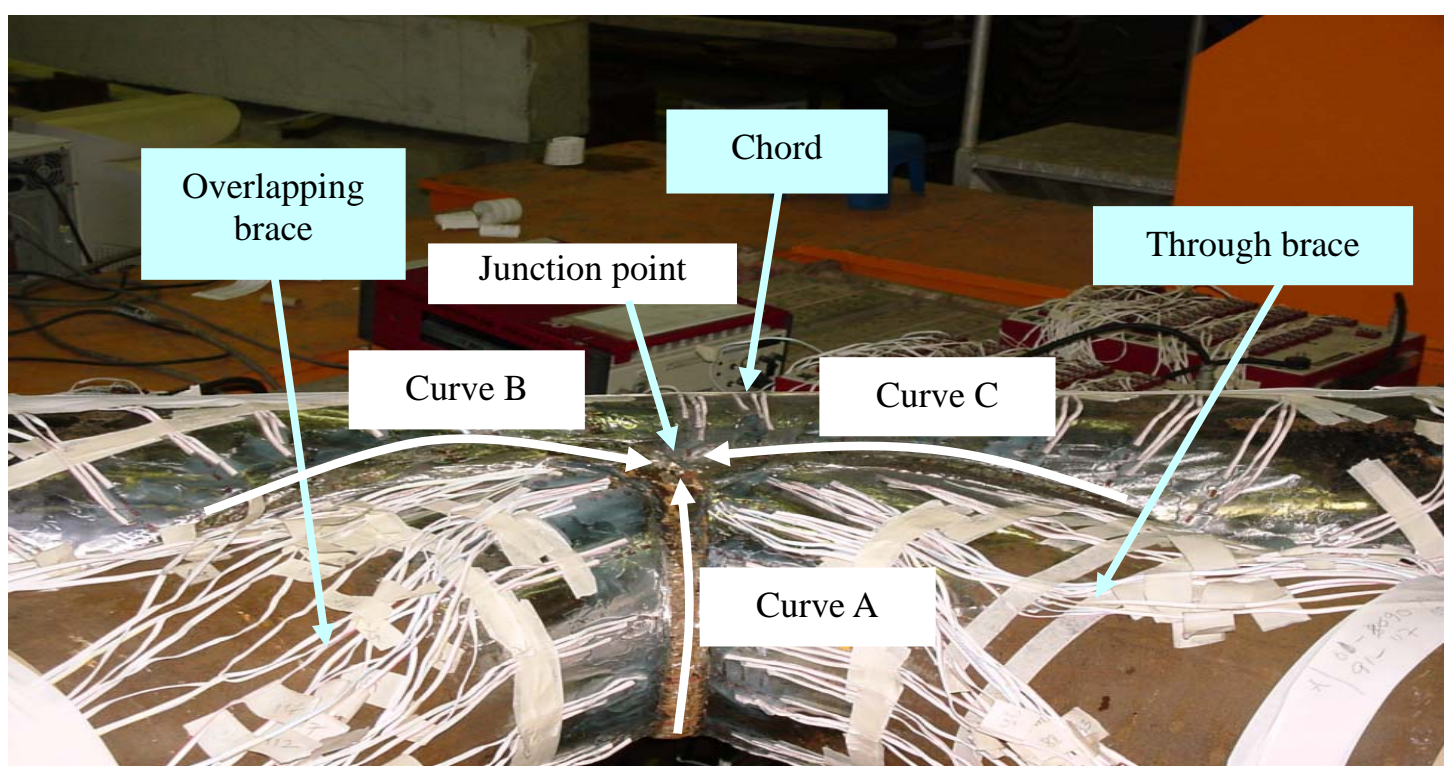

Figure 4. Close up View of the Partially Overlapped Joint and the Three Welding Curves 


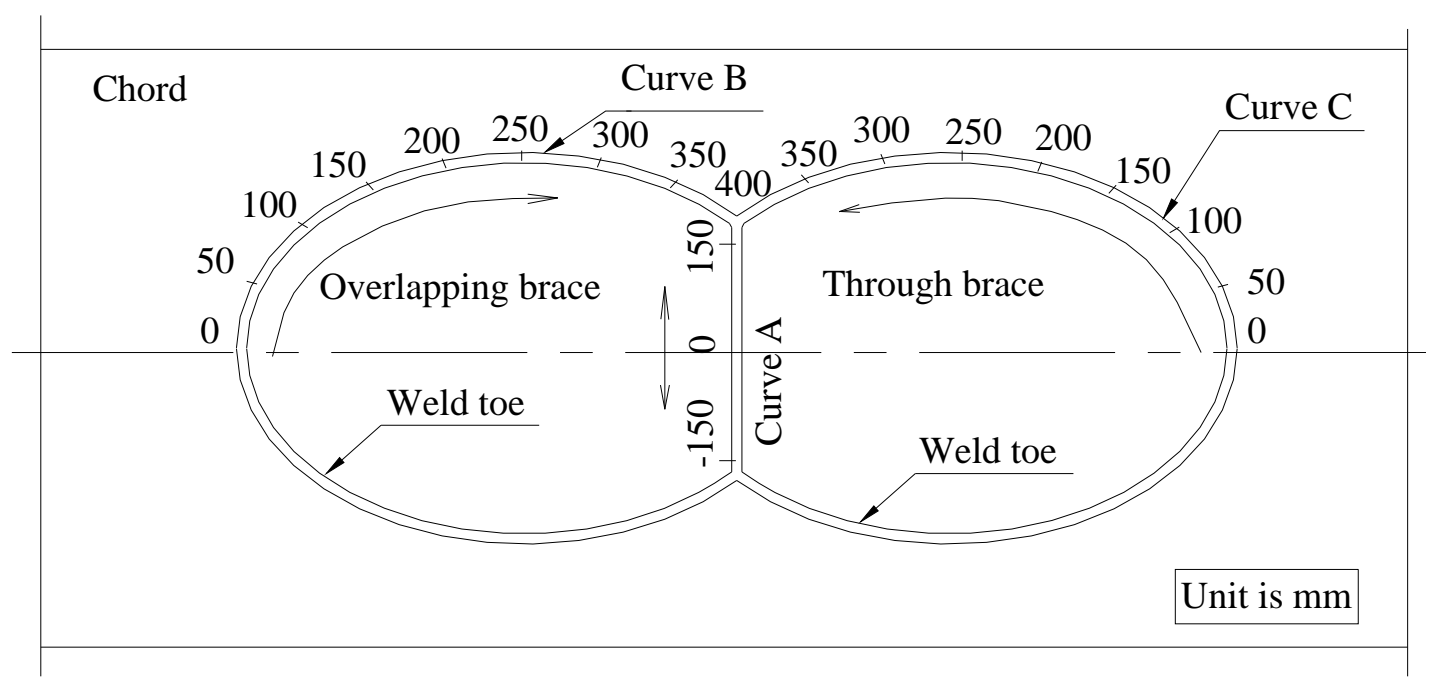

(a) Plan View of the Intersection

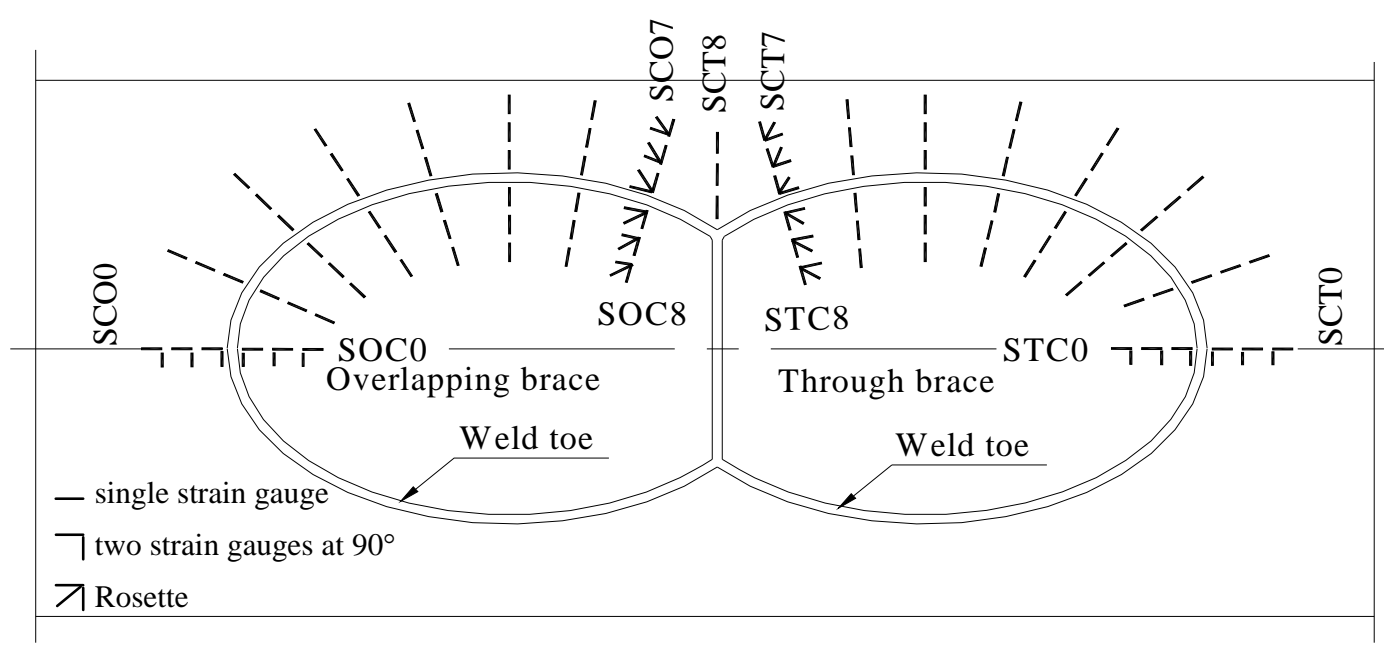

(b) Strain Gauges Locations on Chord and Braces, SI

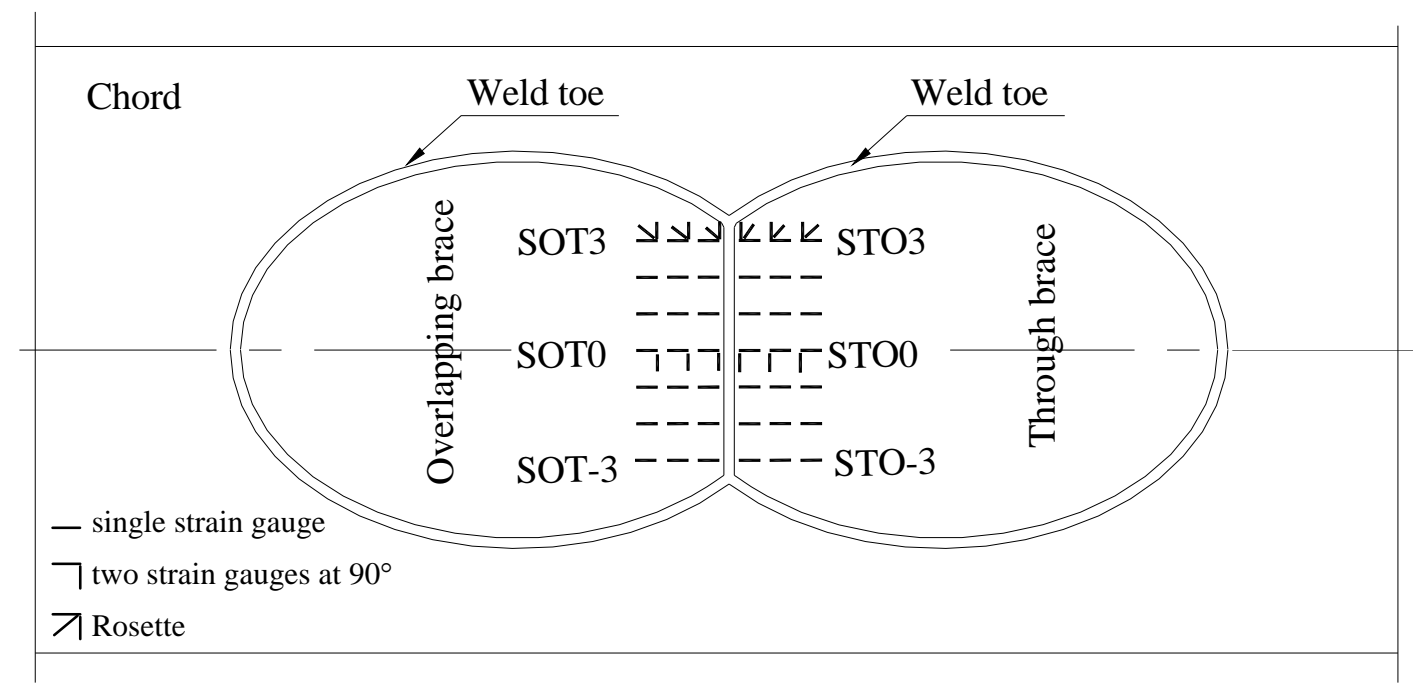

(c) Strain Gauges Locations on Through and Overlapping Braces, SI 


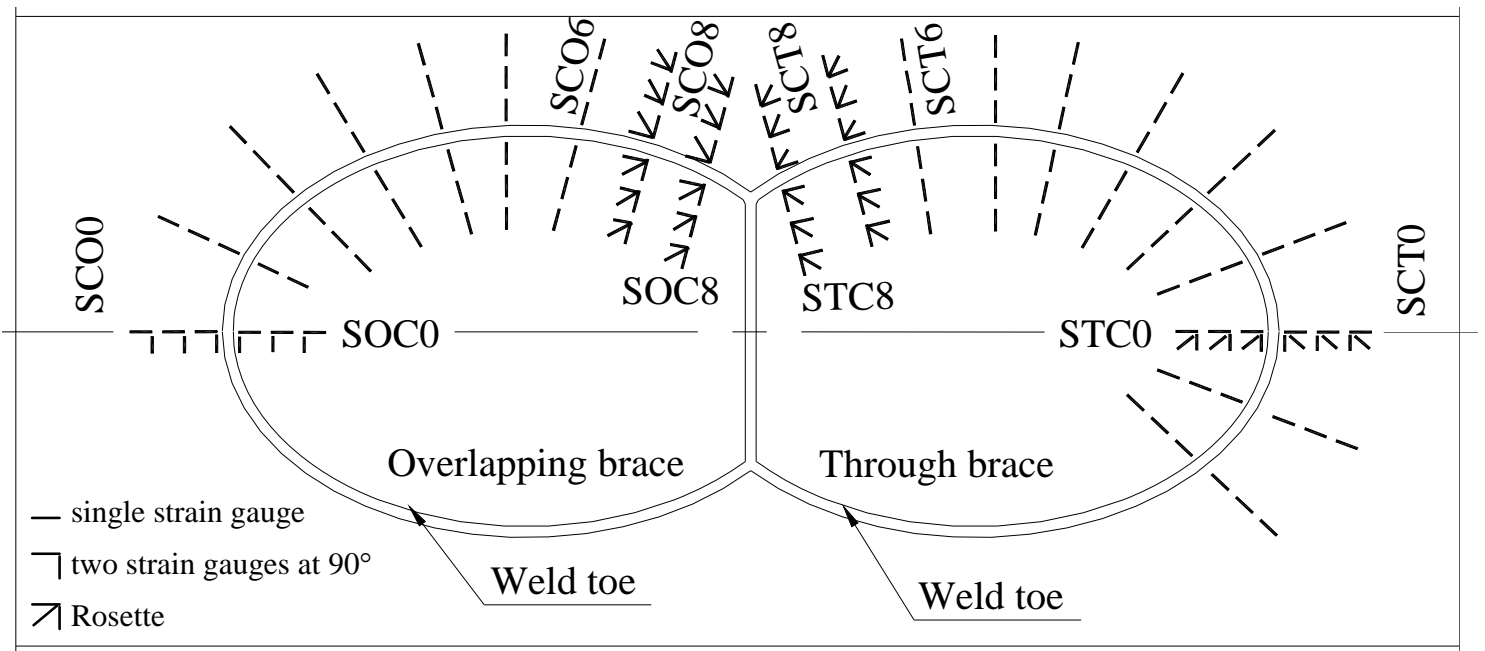

(d) Strain Gauges Locations on Chord and Braces, SII

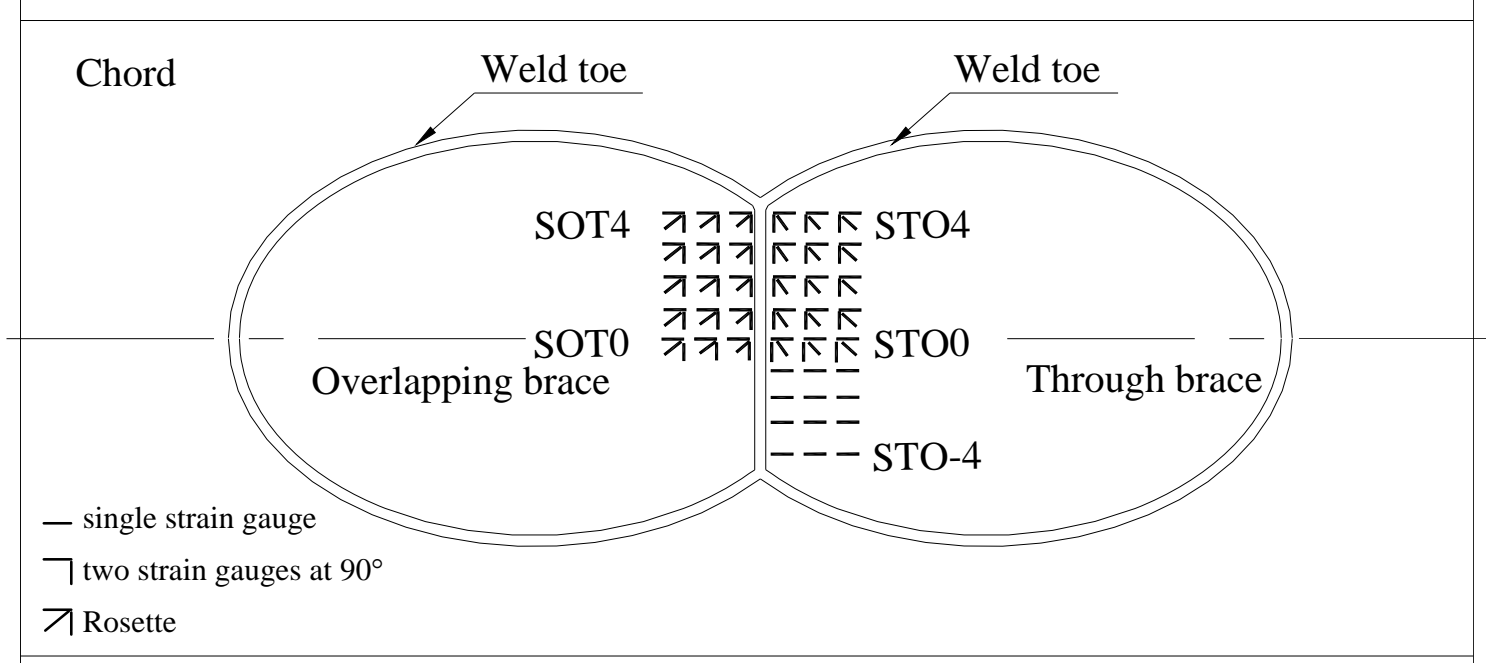

(e) Strain Gauges Locations on through and Overlapping Braces, SII

Figure 5. Strain Gauges Locations for Specimens

Table 3. Peak HSS for the Maximum Basic and Combined Cases Applied in the Test

\begin{tabular}{|c|c|c|c|}
\hline \multirow{2}{*}{ Specimen } & \multirow{2}{*}{ Load cases } & \multicolumn{2}{|c|}{ HSS (MPa) } \\
\hline & & Chord & Brace \\
\hline \multirow{6}{*}{ SI } & AX $(200 \mathrm{kN})$ & 20.5 & 20.81 \\
\hline & IPB $(+45 \mathrm{kN})$ & 110.61 & 345.11 \\
\hline & IPB $(-45 \mathrm{kN})$ & 253.60 & 111.19 \\
\hline & OPB $(30 \mathrm{kN})$ & 89.93 & 127.00 \\
\hline & $\begin{array}{l}\mathrm{AX}(200 \mathrm{kN})+ \\
+\mathrm{IPB}(+45 \mathrm{kN})\end{array}$ & 178.89 & 364.67 \\
\hline & $\begin{array}{c}\mathrm{AX}(200 \mathrm{kN})+ \\
\mathrm{IPB}(-45 \mathrm{kN})\end{array}$ & 285.92 & 125.44 \\
\hline \multirow{6}{*}{ SII } & AX $(100 \mathrm{kN})$ & 14.75 & 7.87 \\
\hline & IPB $(+12 \mathrm{kN})$ & 113.49 & 71.49 \\
\hline & IPB $(-12 \mathrm{kN})$ & 116.24 & 72.11 \\
\hline & OPB $(16 \mathrm{kN})$ & 109.58 & 80.10 \\
\hline & $\begin{array}{l}\text { AX }(100 \mathrm{kN})+ \\
+\mathrm{IPB}(+12 \mathrm{kN})\end{array}$ & 121.9 & 95.44 \\
\hline & $\begin{array}{l}\text { AX }(100 \mathrm{kN})+ \\
\text { IPB }(-12 \mathrm{kN})\end{array}$ & 97.44 & 56.42 \\
\hline
\end{tabular}




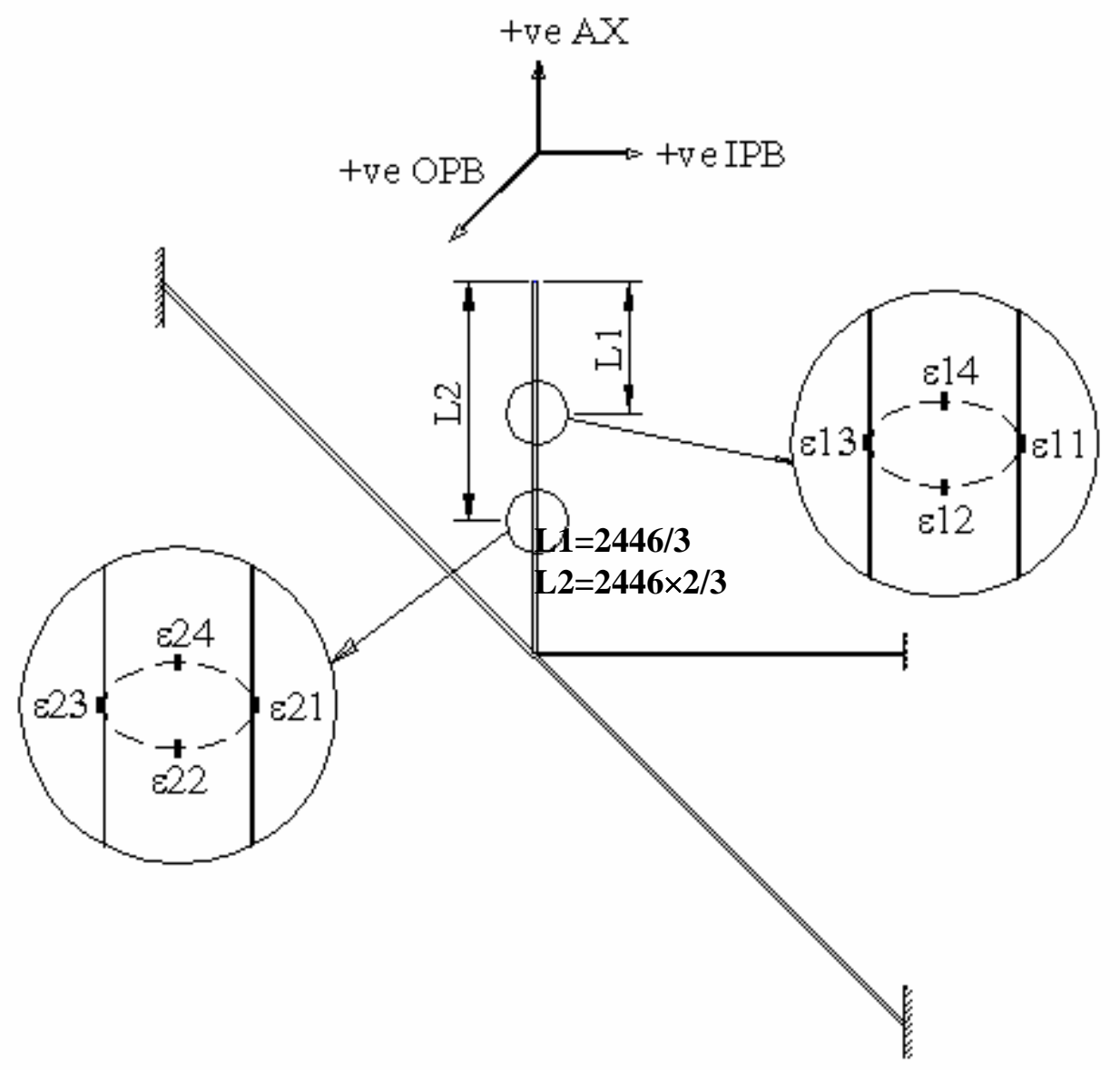

Figure 6. Eight Strain Gauges at the Midway of the through Brace

\section{STATIC TEST PROCEDURE}

In the static test, a series of basic loading cases and combinations of them were applied. The basic load cases were employed to obtain the SCF and the HSS distributions from the specimens and to validate the results against the published equations (Efthymiou and Durkin [1]). Prior to the actual test, the specimen was subjected to at least six loading and unloading sequences. This precaution shall test for the satisfactory performance of strain gauges and eliminated any drift of strain measurements due to the fabrication of the joints. In the actual test, each specimen was first subjected to an incremental static load on one axis, and the strains were checked against linearity and zero drift to indicate shakedown of residual stress. The eight strain gauges installed at the cross sections of the joint members were monitored by data logger to manage the applied loads in such a way that secondary loads would not be involved. The actuators were then ramped to the predetermined loads. During the static test, in order to ensure that the joint remained fully elastic, the maximum static load applied was carefully computed so that the peak HSS generated in all loading cases shall not exceed $85 \%$ of the corresponding material yield stress of the sections (Table $3)$. It should be mentioned that while only positive value of AX and OPB loadings were applied in the test, both positive and negative IPB loadings (Figure 3) were applied. During the tests, the actuators were ramped to the maximum load in at least six loading increments. At each step, the actuators were held in place and the strain readings were recorded. The loads were then increased to the next level and measurements were repeated. After reached the maximum load, the above steps were repeated by releasing the applied load in several increments to zero. 


\section{TEST RESULTS}

\section{SCF Computations}

At locations where only the single strain gauge arrangement was used, the strain values measured were directly converted to the stress values by multiple them with the Young's modules and the stress-strain conversion factors (Lee et al. [17]). Quadratic extrapolation was then applied to obtain the stress at the weld toe for SCF computation. At locations where the two strain gauges arrangement was used, the corresponding strain concentration factor $(S N C F)$ is first computed as

$$
S N C F=\frac{H S S N}{S N_{\text {nominal }}}
$$

where $S N_{\text {nominal }}$ is the nominal strain computed from the eight strain gauges readings at the center of brace sides. The SCF value is then computed using the following equation:

$$
S C F=\operatorname{SNCF} \frac{\left(1+v \xi_{\|} / \xi_{\perp}\right)}{\left(1-v^{2}\right)}
$$

In Eq. 2 strains $\xi_{\perp}$ and $\xi_{\|}$are, respectively the perpendicular and the parallel strain components recorded by the strain gauges and $v=0.3$ is the Poisson's ratio. Eventually, quadratic extrapolation was again employed to compute the $S C F$ at the weld toe. At location where rosettes were deployed, the principal strain and stress could be directly computed and the SCF values at weld toe were then obtained by extrapolations.

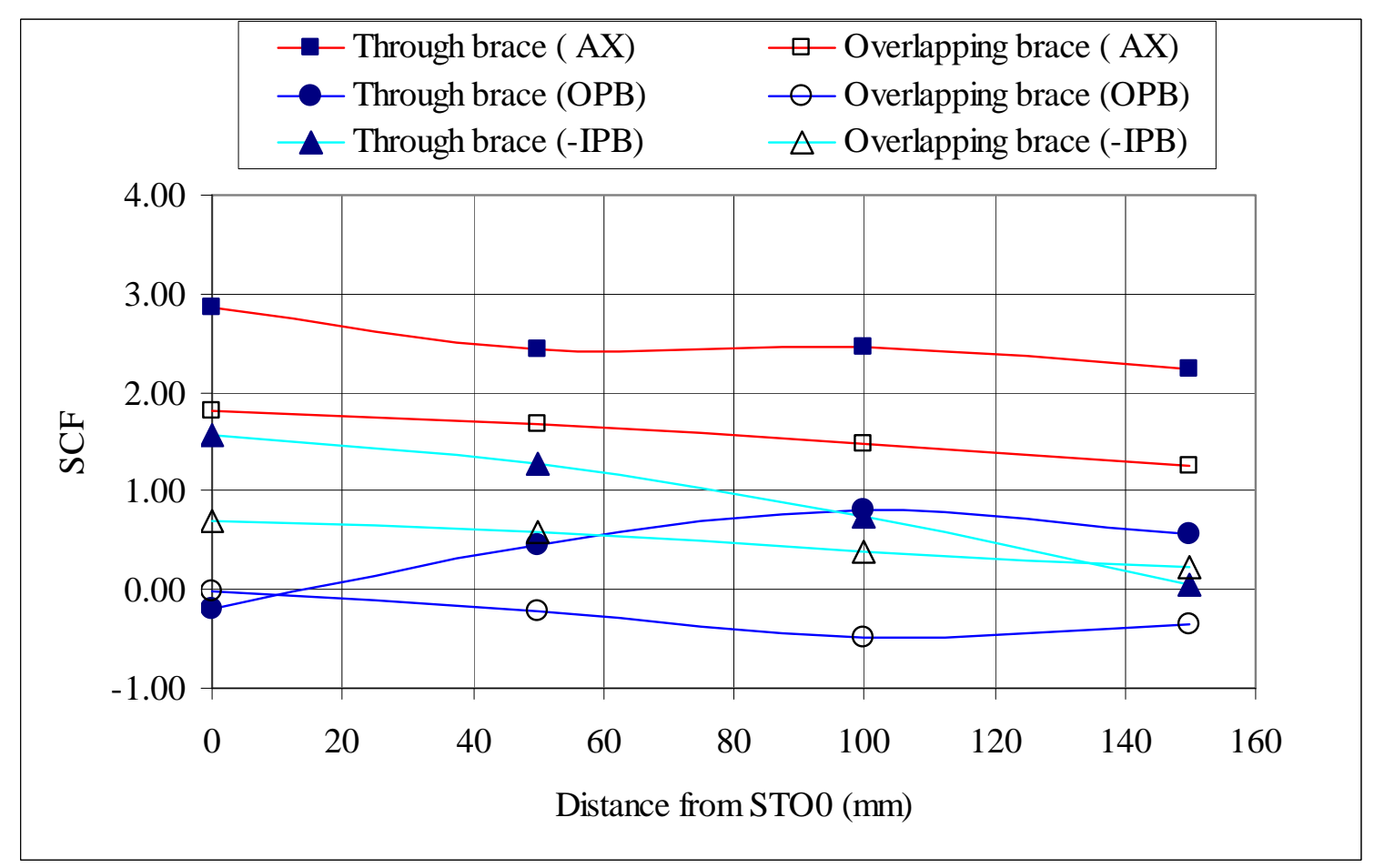

(a) Curve A 


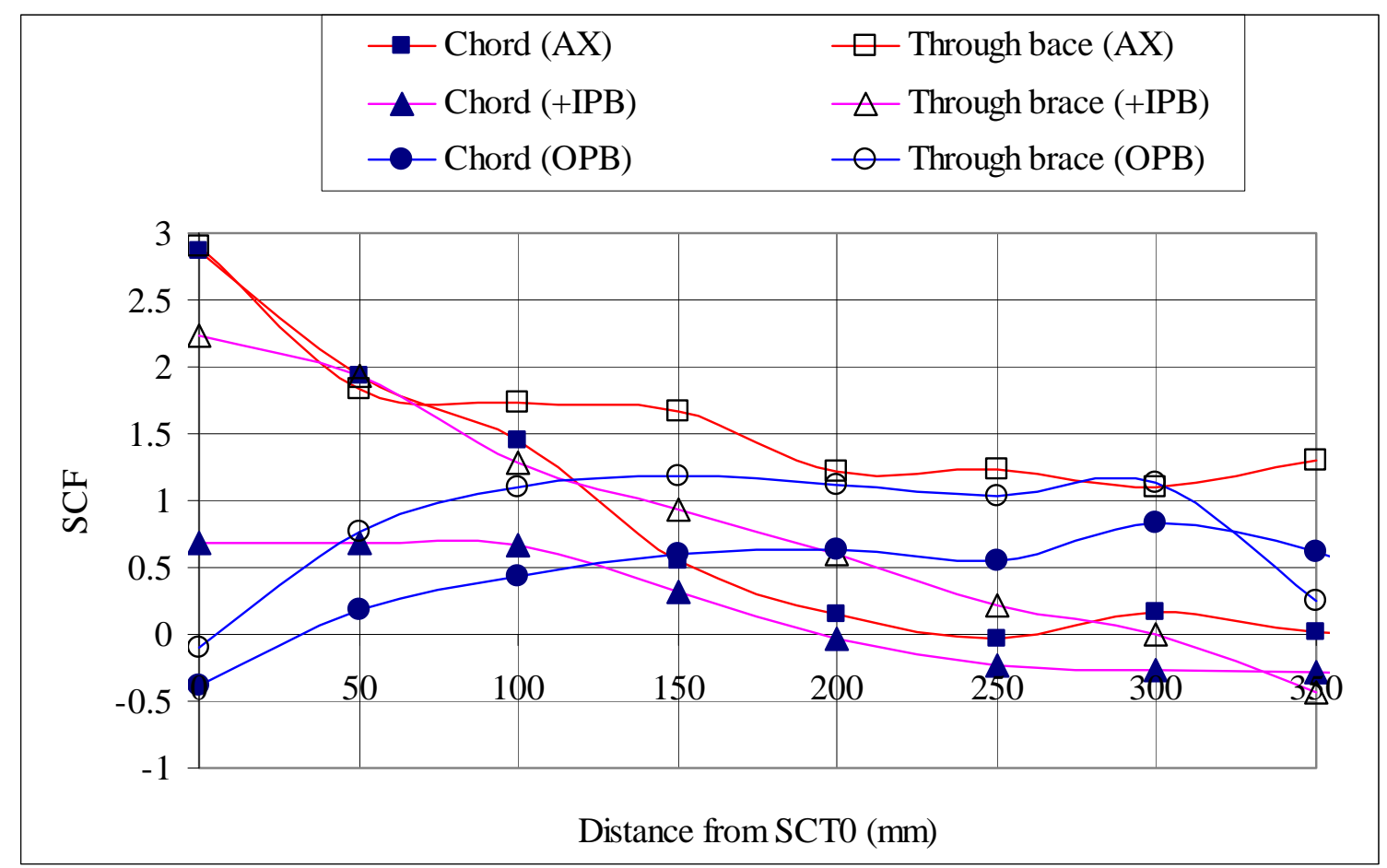

(b) Curve C

Figure 7. Variations of SCF along the Welding Curves A and C of SI

\section{SCF Distributions}

For Specimen I, it is found that critical SCF values were induced along Curve A and Curve B. In particular, a positive and a negative IPB loading induced high values of SCF along Curve $\mathrm{C}$ and Curve A, respectively. The SCF distributions along Curves A and C for Specimen I under different basic loading cases are shown in Figure 7(a) and 7(b), respectively. In Figure 7(a), the SCF distributions along both the through and the overlapping braces are plotted. From Figure 7(a), it can be seen that in general, the SCF distributions along the through brace are higher than that along the overlapping brace. For Curve C, as shown in Figure 7(b) for the SCF distributions along the chord and the through brace, the SCF distributions along the through brace are higher than that along the chord.

For Specimen II, similar plots for the SCF distributions are shown in Figure 8(a) and Figure 8(b) for Curve A and Curve C, respectively. From Figure 8(a), it is again observed that for Curve A under the same basic loadings, the SCF induced along the through brace are in general higher than that along the overlapping brace. However, for Curve C, it is found that the maximum SCF induced along the chord is higher than that along the through brace. Hence, it could be concluded that besides the magnitude, the location of maximum SCF could also be influenced by the geometrical parameters of the joint. 


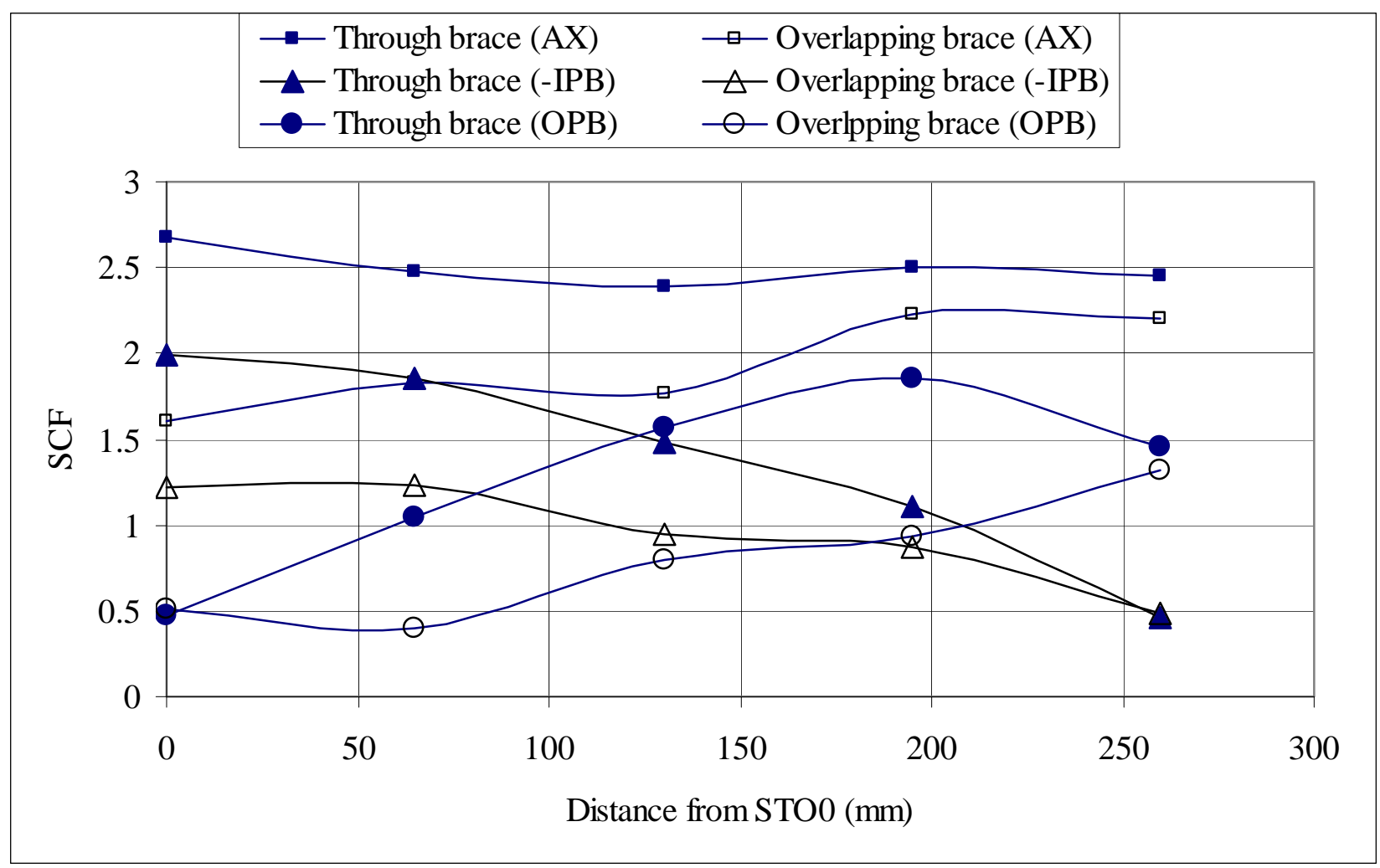

(a) Curve A

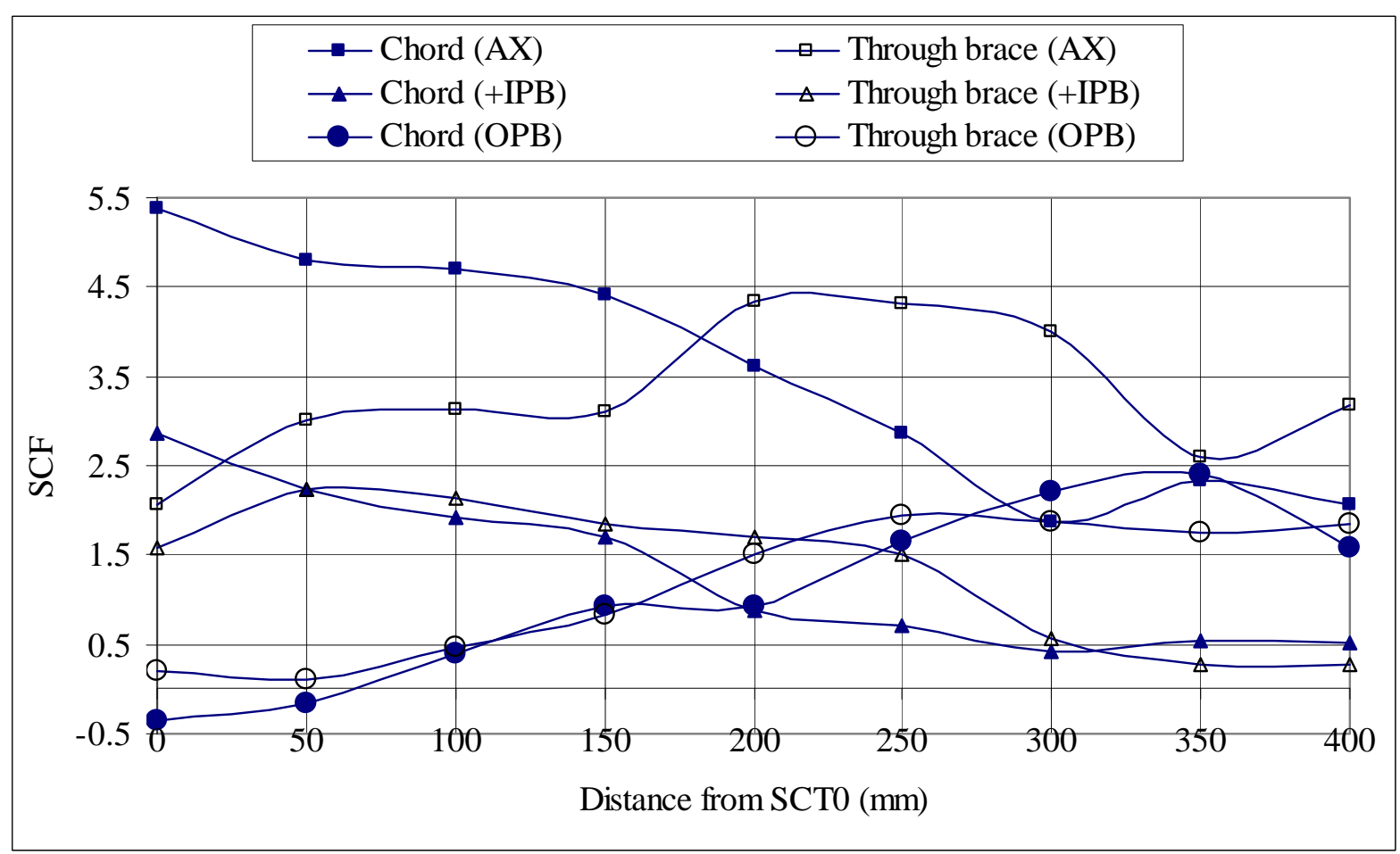

(b) Curve C

Figure 8. Variations of SCFs along the Welding Curves A and C of SII 


\section{HSS Distributions}

In this study, three different approaches were employed to evaluate the HSS of the joints tested under combined loading conditions. Besides direct strain and stress measurements obtained during the experimental study, the standard superposition method (Zhao et al. [3]) was also employed to compute the HSS from the SCF values obtained from the basic load cases. When the superposition method is used, for the combined load cases, $\sigma(\boldsymbol{p})$, the stress at a given point $\boldsymbol{p}$ at the weld toe is calculated as

$$
\sigma(\boldsymbol{p})=S C F_{A X}(\boldsymbol{p}) \times \sigma_{n-A X}+S C F_{I P B}(\boldsymbol{p}) \times \sigma_{n-I P B}+S C F_{O P B}(\boldsymbol{p}) \times \sigma_{n-O P B}
$$

where $S C F_{A X}(\boldsymbol{p}), S C F_{I P B}(\boldsymbol{p})$ and $S C F_{O P B}(\boldsymbol{p})$ are, respectively, the SCFs at point $\boldsymbol{p}$ for the AX, the IPB and the OPB loads. $\sigma_{n-A X}, \sigma_{n-I P B}$ and $\sigma_{n-O P B}$ are the corresponding nominal stresses. Finally, HSS values were also evaluated by carrying out a detailed finite element analysis using 3D solid elements model developed for fatigue performance study (Chiew et al. [18]). Figure 9 shows the 3D solid finite element meshes adopted in the numerical modelings. From Figure 9, it can be seen that high density of small elements were placed along the intersection part of the joint. Note that a similar quadratic extrapolation method was also adopted to extract the HSS values from the FE models. Hence, the HSS values obtained from numerical modeling could be directly compared with the corresponding results obtained from the experiments and the superposition method.

After some detail comparisons among all the results obtained, it is found that when the joints were subjected to combine AX and IPB loadings, peak HSS was induced along Curve C. Figure 10(a) and Figure 10(b) show the HSS distributions obtained by the three approaches along Curve $C$ for Specimens I and II, respectively. For Specimen I, it can be seen that for all the three approaches used, HSS distributions along the through brace are higher than the corresponding distribution along the chord. Note that this observation is different from most results obtained in other T/Y and gapped K-joints studies in which the peak HSS location was almost all reported to be located along the chord side of the joint. For Specimen II, from Figure 10(b), it can be concluded that under the AX and IPB loading combination, the peak HSS is located along the chord side of the joint while the results obtained from all three different approaches show reasonable agreement. Hence, it can be concluded that when one would like to carry out fatigue assessment of an uncracked partially overlapped CHS K-joint, cares shall be paid on the locations of the peak HSS which could either be located along the chord side or the brace side of the joint.

\section{Comparison with Efthymiou's Formulae}

The maximum SCF values obtained from the tests under the AX and IPB load cases and the corresponding values obtained by using Efthymiou's formulae [1] along the Curve $\mathrm{C}$ are plotted in Figure 11 and Figure 12 for Specimens I and II, respectively. In addition, the maximum SCF values for all loading cases obtained from the test, from the FE models and from the Efthymiou's formulae are summarized in Table 4. Note that in Figures 11 and 12, the SCF values from Efthymiou's formulae were plotted as horizontal lines since the these formulae only give a single SCF value but not the distribution along the weld toe. Furthermore, since Efthymiou's formulae do not give any value for the load case of OPB, no comparison was made between the formulae and the experimental results. From Figures 11 and 12 and Table 4, it can be concluded that the Efthymiou's formulae is conservative for both specimens for the IPB loading case. However, they are not always conservative for the AX loading case (e.g. Specimen I, AX loading for both chord and brace side). Hence, the use of these formulae in practical applications may not be always able to yield conservative estimation of the fatigue life of a partially overlapped CHS K-joint. 


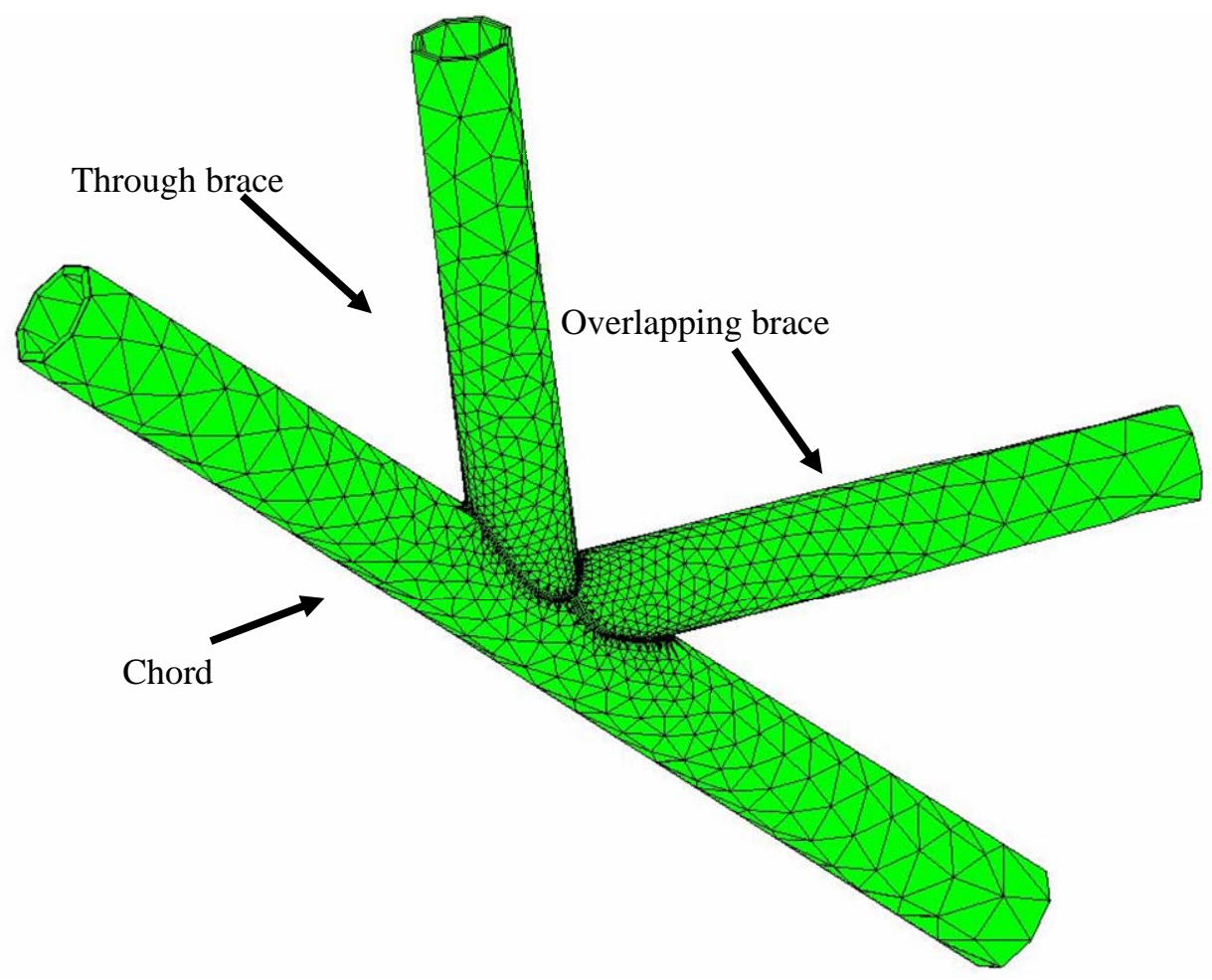

(a) Mesh for SI

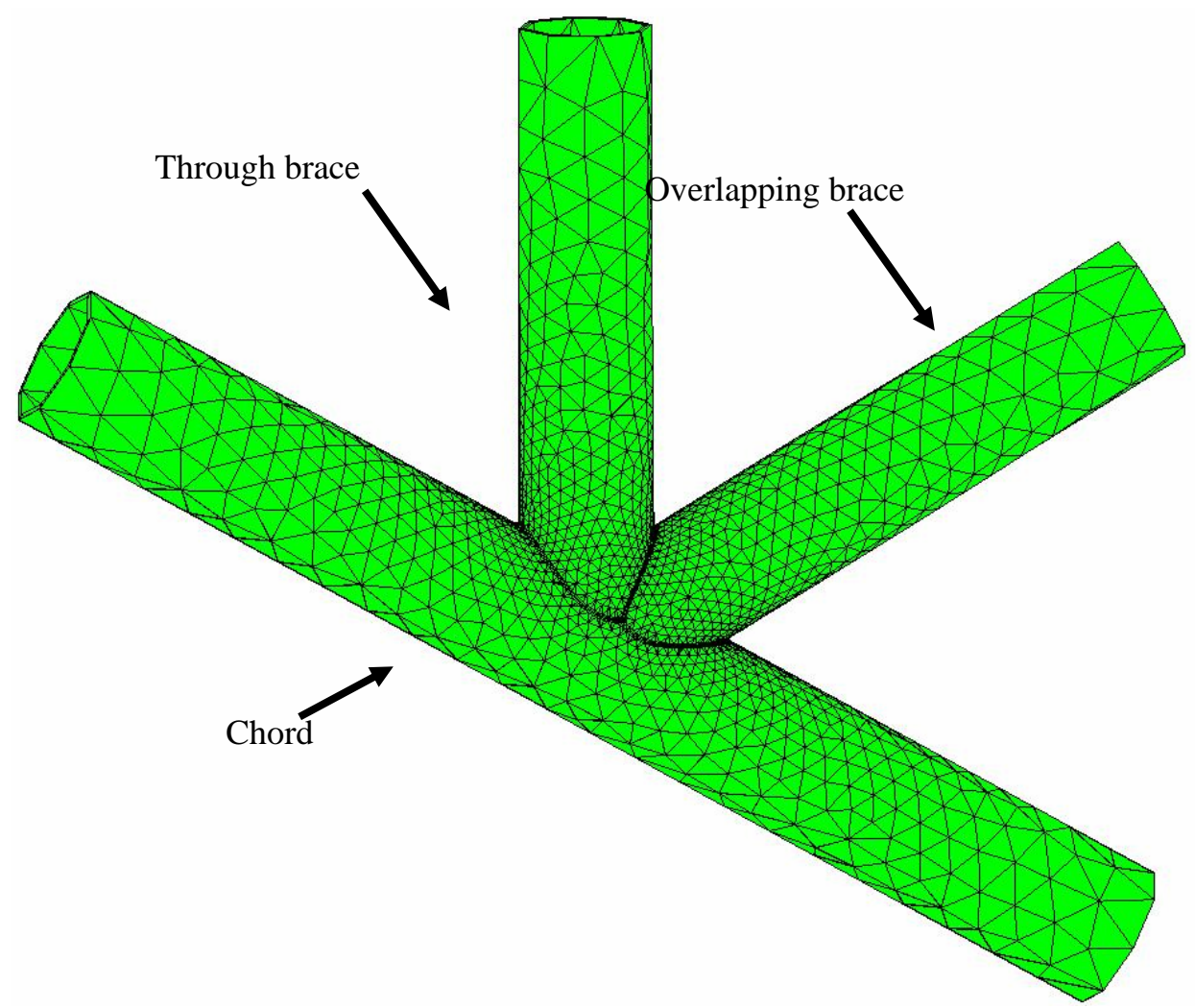

(b) Mesh for SII

Figure 9. Finite Element Meshes used in the Numerical Modeling of the Specimens 


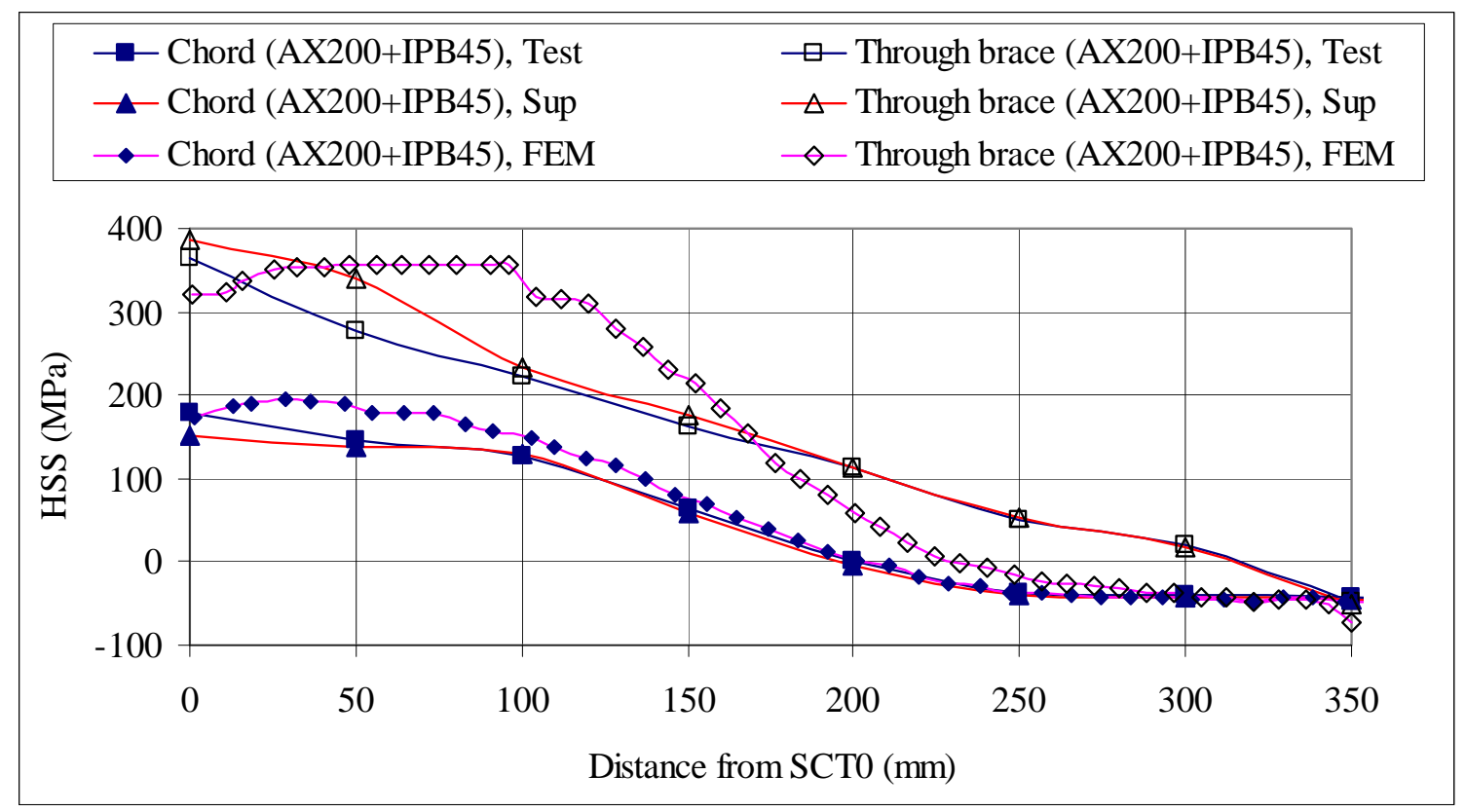

(a) Results for SI, Curve C

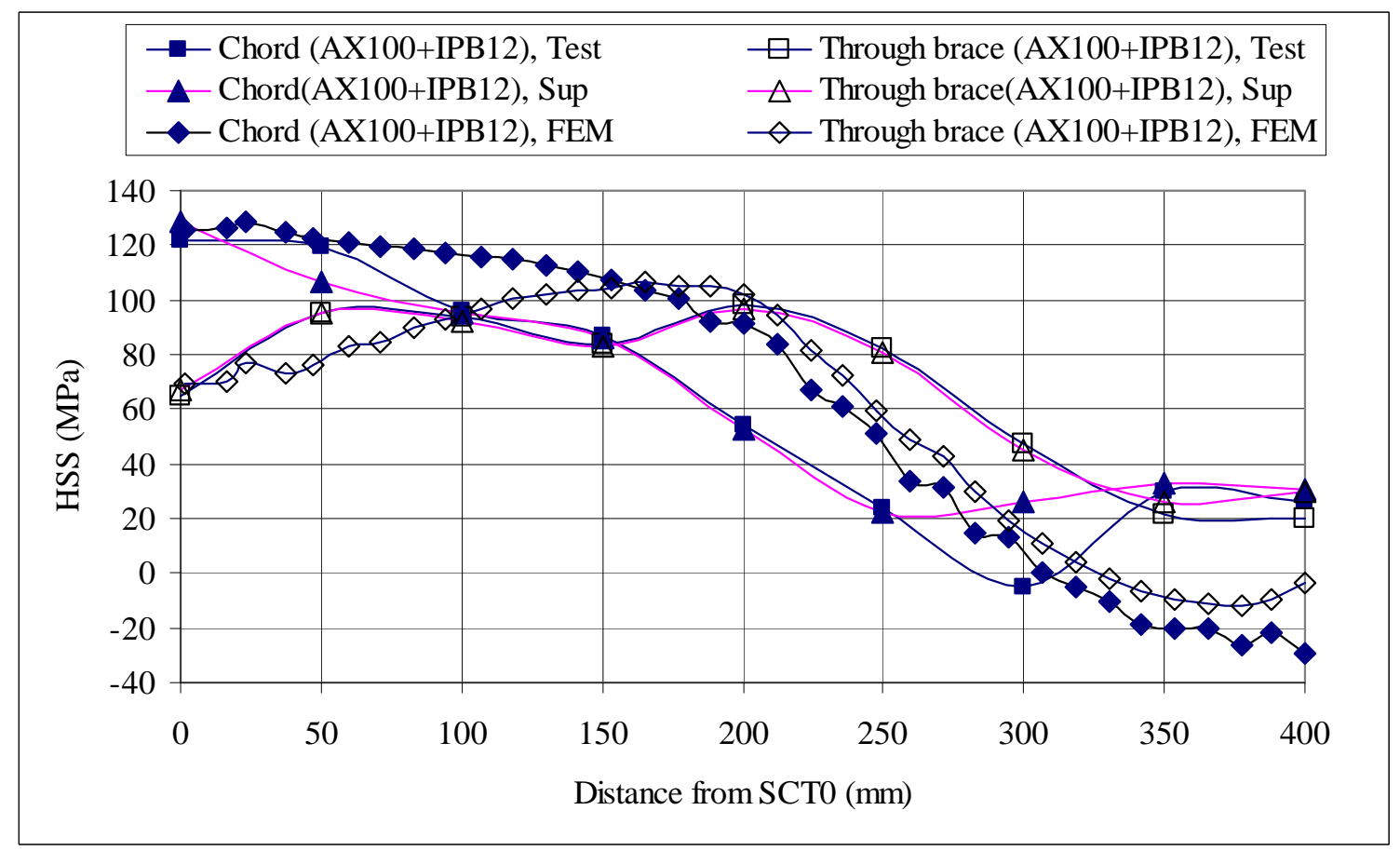

(b) Results for SII, Curve C

Figure 10. Comparison of HSS Obtained from Test, Superposition Method and FE Analyses 


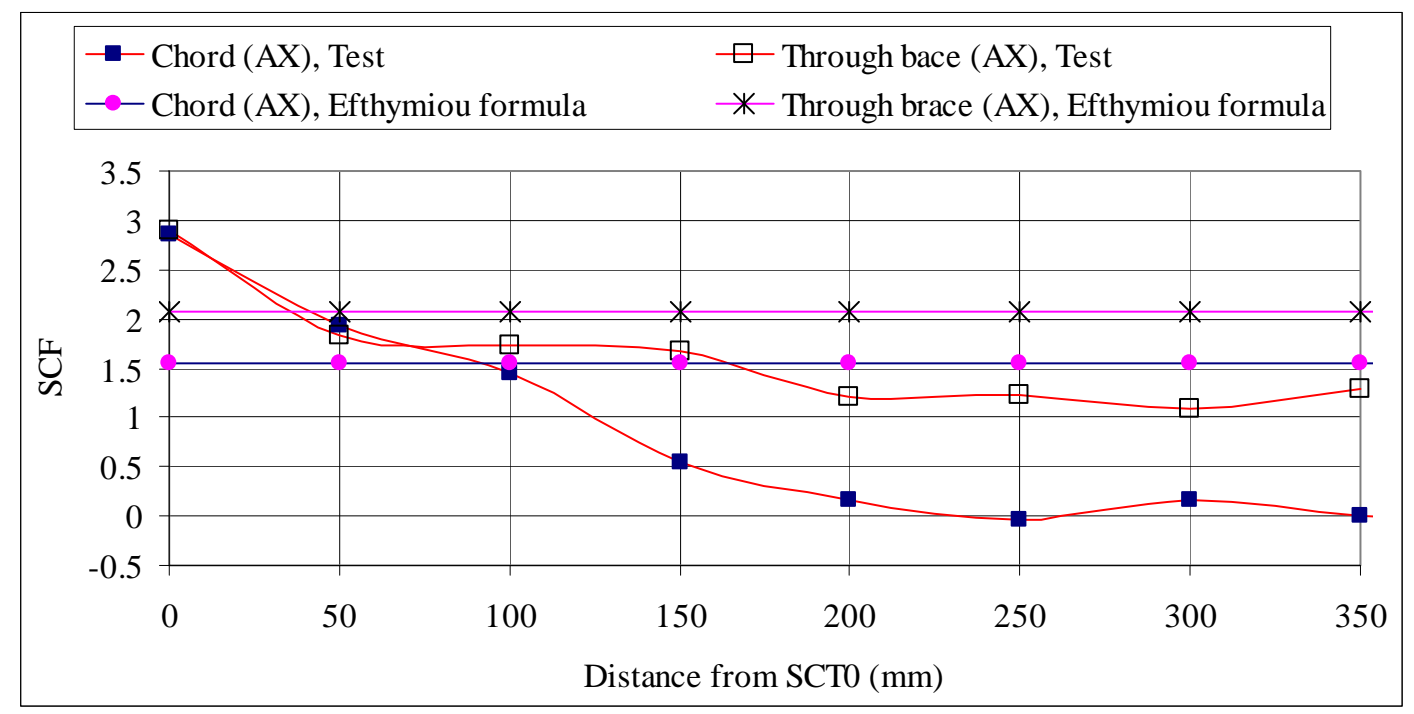

(a) Curve C, AX Loading

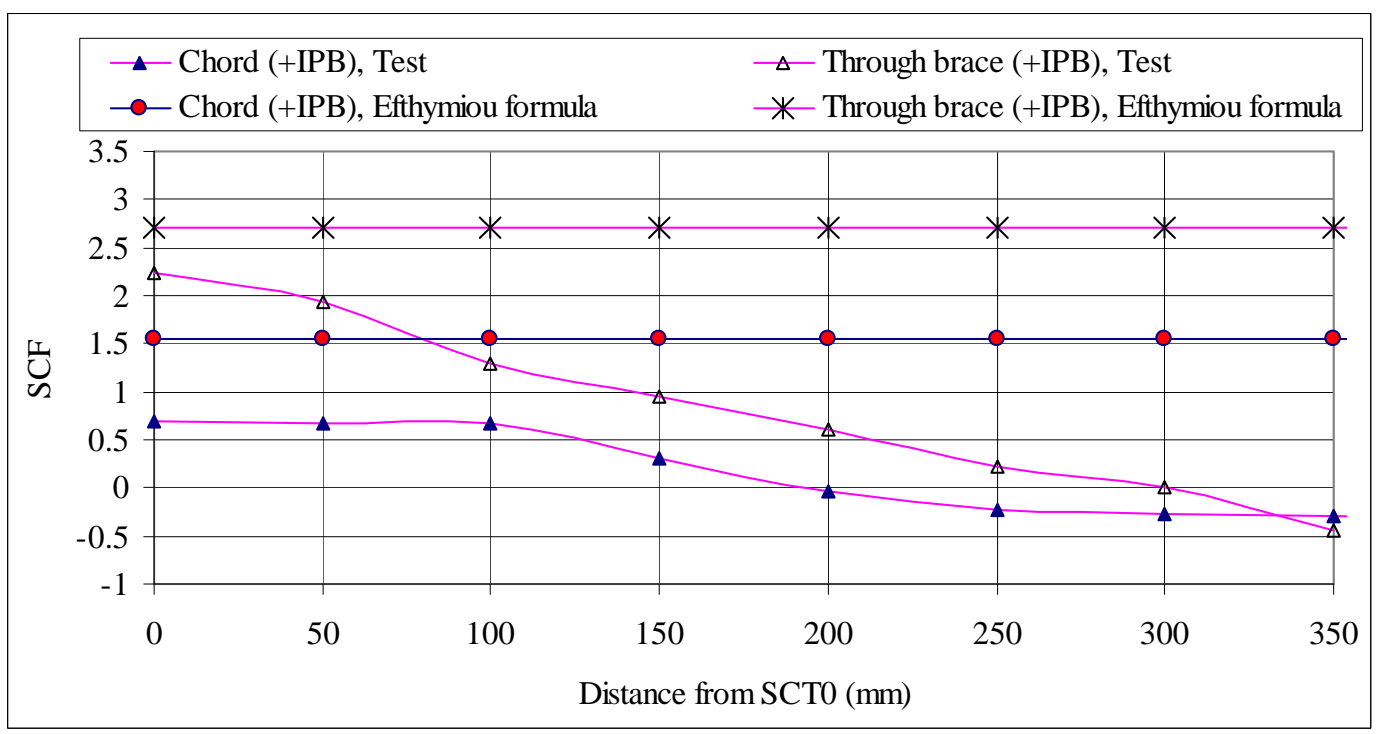

(b) Curve C, +IPB Loading

Figure 11. Comparison of SCF Variations Obtained from Test and Efthymiou's Formulae, SI. 


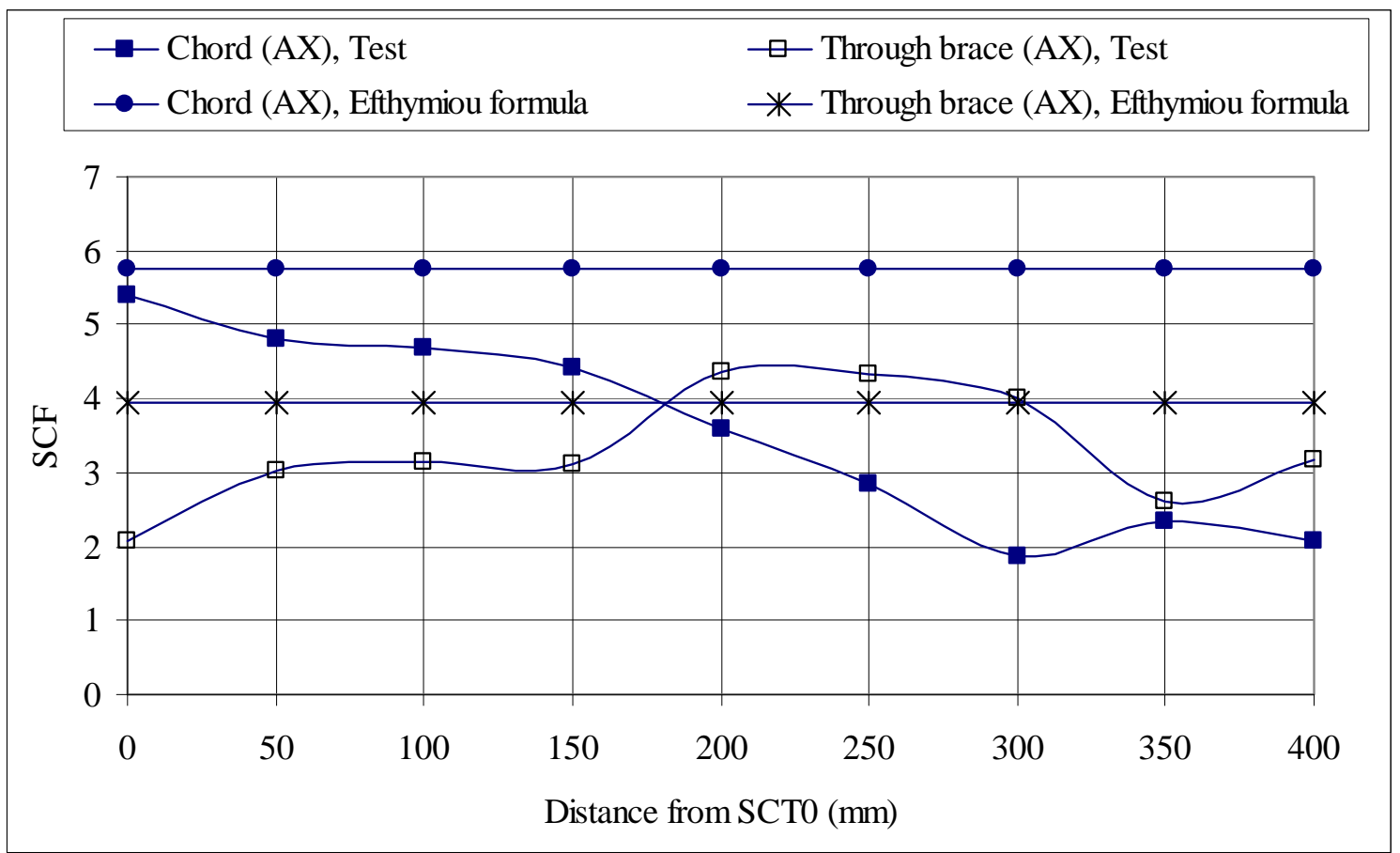

(a) Curve C, AX Loading

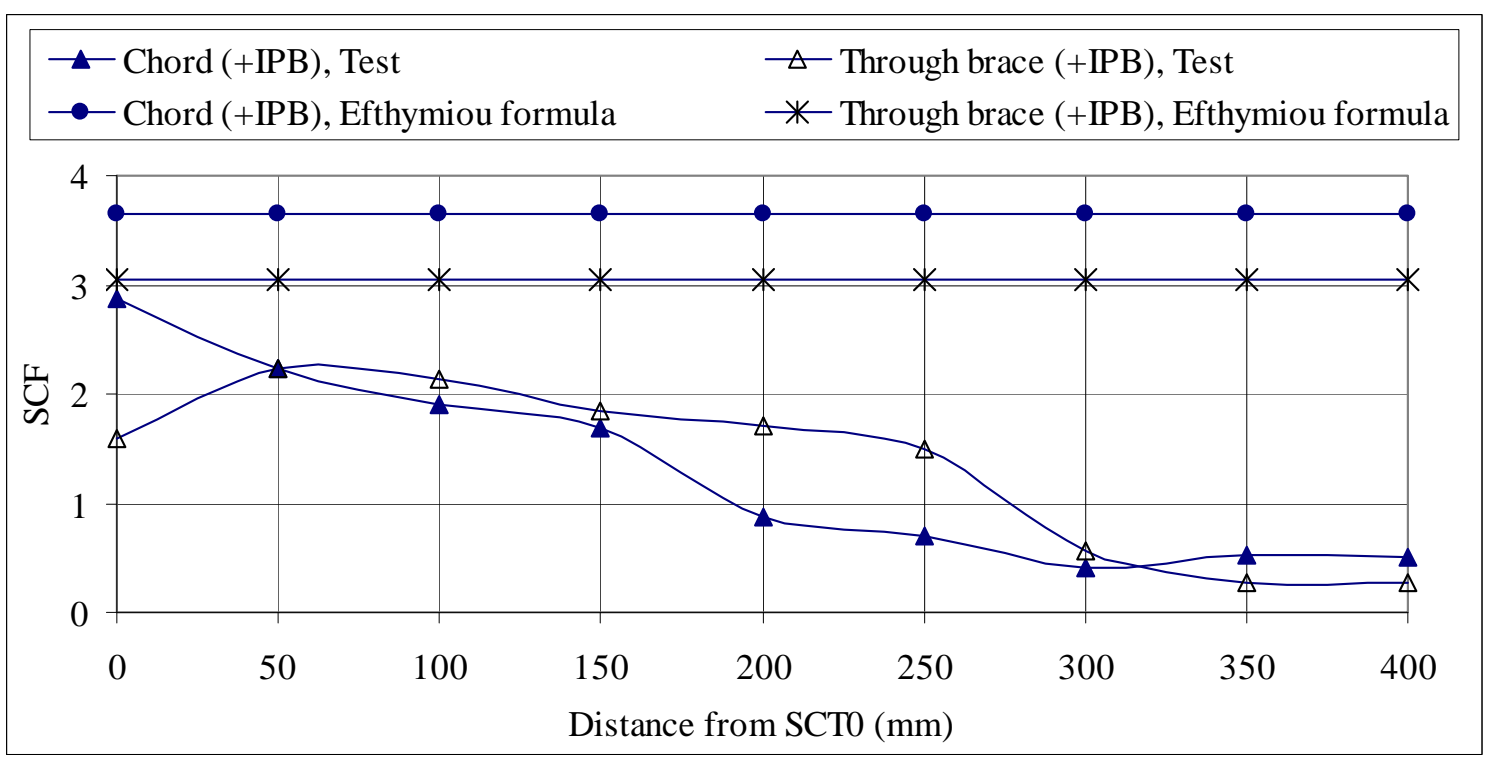

(b) Curve C, +IPB Loading

Figure 12. Comparison of SCF Variations Obtained from Test and Efthymiou's Formulae, SII 
Table 4. Summary of SCF for Basic Loading Cases Obtained from Test, Efthymiou's Formulae and FE Analyses

\begin{tabular}{|c|c|c|c|c|c|}
\hline \multirow{3}{*}{$\begin{array}{l}\text { Basic load } \\
\text { cases }\end{array}$} & \multirow{3}{*}{ Methods } & \multicolumn{4}{|c|}{ Specimen } \\
\hline & & \multicolumn{2}{|c|}{ SI } & \multicolumn{2}{|c|}{ SII } \\
\hline & & Chord & Brace & Chord & Brace \\
\hline \multirow{3}{*}{ AX } & Test & 2.86 & 2.9 & 5.38 & 4.32 \\
\hline & Efthymiou & 1.55 & 2.08 & 5.75 & 3.94 \\
\hline & FEM & 0.98 & 2.29 & 3.18 & 2.71 \\
\hline \multirow{3}{*}{+ IPB } & Test & 0.8 & 2.32 & 2.62 & 2.09 \\
\hline & Efthymiou & 1.55 & 2.71 & 3.65 & 3.05 \\
\hline & FEM & 1.61 & 2.87 & 3.92 & 3.38 \\
\hline \multirow{3}{*}{-IPB } & Test & 1.56 & 0.68 & 1.99 & 1.23 \\
\hline & Efthymiou & - & - & - & - \\
\hline & FEM & 1.56 & 0.69 & 1.99 & 0.69 \\
\hline \multirow{3}{*}{ OPB } & Test & 0.72 & 0.99 & 2.40 & 1.94 \\
\hline & Efthymiou & - & - & - & - \\
\hline & FEM & 1.71 & 1.48 & 3.11 & 1.85 \\
\hline
\end{tabular}

\section{CONCLUSIONS}

In this paper, a carefully planned experimental study was carried out to investigate the SCF and the HSS distributions along the joint intersection of two full scale partially overlapped CHS K-joints. The experimental results show that, depends on the geometrical parameters of the joint, the maximum SCF could locate on either the brace side or the chord side of the joint. This is different from the previous research findings on T-, Y and K-joints with gap in which the maximum SCF normally locates on the chord side only. In addition, the experimental results also shows that Ethymiou's formulae [1] are conservative only when the joints were subjected to IPB loading, but not for the case of AX loading. Hence, it is probably fair enough to say that the Efthymiou's formulae, which are currently the only formulae available in literature, may not be completely suitable for the design of partially overlapped CHS K-joints. Therefore, there is a need to develop a new design recommendation. Towards the end, the numerical examples given in this paper shown that reliable SCF values could be obtained from a carefully constructed FE model. Hence, further research works on both the experimental and parametric numerical studies could be conducted to obtain a more complete picture for the responses of this type of joints under different loading conditions.

\section{NOTATIONS AND ABBREVIATIONS}

$L_{C} \quad$ Length of Chord

D $\quad$ Outside chord diameter

$d \quad$ Outside brace diameter

$e \quad$ Eccentricity

$T \quad$ Chord wall thickness

$t \quad$ Brace wall thickness

$O_{V} \quad$ Percentage of overlapping

$\alpha \quad$ Chord length parameter (2L/D)

$\beta \quad$ Brace-to-chord diameter ratio (d/D)

$\gamma \quad$ Chord radius-to-wall thickness ratio (D/2T)

$\theta_{1} \quad$ Angle between chord and through brace 


$\begin{array}{ll}\theta_{2} & \text { Angle between chord and overlapping brace } \\ \tau & \text { Wall thickness ratio (t/T) } \\ \xi_{\perp} & \text { perpendicular strain component } \\ \xi_{\|} & \text {parallel strain component } \\ \sigma(\boldsymbol{p}) & \text { stress at a given point } \boldsymbol{p} \text { at the weld toe } \\ S N_{\text {nominal }} & \text { nominal strain } \\ S C F_{A X}(\boldsymbol{p}) & \text { SCFs at point } \boldsymbol{p} \text { for the AX load } \\ S C F_{I P B}(\boldsymbol{p}) & \text { SCFs at point } \boldsymbol{p} \text { for the IPB load } \\ S C F_{O P B}(\boldsymbol{p}) & \text { SCFs at point } \boldsymbol{p} \text { for the OPB load } \\ \sigma_{n-A X} & \text { nominal stress for the AX load } \\ \sigma_{n-I P B} & \text { nominal stress for the IPB load } \\ \sigma_{n-O P B} & \text { nominal stress for the OPB load } \\ \mathrm{CHS} & \text { Circular hollow section } \\ \text { AX } & \text { Axial load } \\ \text { IPB } & \text { In-plane bending } \\ \text { OPB } & \text { Out-of-plane bending } \\ \text { HSS } & \text { Hot spot stress } \\ \text { SCF } & \text { Stress concentration factor } \\ \text { SNCF } & \text { strain concentration factor }\end{array}$

\section{REFERENCES}

[1] Efthymiou, M. and Durkin, S., "Stress Concentrations in $\mathrm{T} / \mathrm{Y}$ and Gap/Overlap K-Joints, Behavior of Offshore Structures”, Elsevier, Amsterdam, Netherlands, 1985, pp. 429-440.

[2] BOMEL, "Joint Industry Funded Program: Analytical and Experimental Investigation of the Behaviour of Tubular Frames”, Final Report, Maidenhead, UK, 1992.

[3] Zhao, X.L., Herion, S., Packer, J.A., Puthli, R., Sedlacek, G., Wardenier, J., Weynand, K., van Wingerde, A. and Yeomans, N., "Design Guide for Circular and Rectangular Hollow Section Joints under Fatigue Loading”, CIDECT Publication No. 8, TUV-Verlag, Germany, 2001.

[4] EC3, "Design of Steel Structures - Part 1.1: General Rules and Rules for Building”, ENV 1993-1-1, Eurocode 3, European Committee for Standardisation (CEN), 1992.

[5] Bouwkamp, J.G., "Research on Tubular Connections in Structural Work", Welding Research Council Bulletin, USA, 1961.

[6] Bouwkamp, J.G., “Concept of Tubular-Joint Design”, Proceedings ASCE, Journal of Structural Division, USA, 1964.

[7] Healy, B.E. and Buitrago, J., "Extrapolation Procedures for Determining SCFs in Mid-Surface Tubular Joint Models”, Conference of Tubular Structures, 1994, Vol. VI, pp.651-659.

[8] Dexter, E.M. and Lee, M.M.K., "Static Strength of Axially Loaded Tubular K Joints. I: Behaviour”, Journal of Structural Engineering, Vol. 125, No. 2, pp. 194-201, 1999.

[9] Dexter, E.M. and Lee, M.M.K., "Static Strength of Axially Loaded Tubular K Joints. I: Ultimate Capacity”, Journal of Structural Engineering, 1999, Vol. 125, No. 2, pp. 202-210.

[10] Dexter, E.M., Lee, M.M.K. and Kirkwood, M.G., "POCHS K-Joints in Circular Hollow Sections under Axial Loading (An Investigation of the Factors Affecting the Static Strength Using Numerical Modelling), Journal of Offshore Mechanics and Artic Engineering, 1996, Vol. 118, pp. 53-61.

[11] Tizani, W.M.K., Yusurf, K.O., Davies, G. and Smith, N.K., “A Knowledge Based System to Support Joint Fabrication Decision Making at the Design Stage - Case Study for CHS Trusses”, Proceedings of the 7th International Symposium on tubular structures, Hungary, 1996, pp. 483-489. 
[12] Fessler, H., Little, W.J.G. and Shellard, I.J., "Elastic Stress Due to Axial Loading of Tubular Joints with Overlap, BOSS’79, USA, 1979.

[13] Gibstein, M.B., "Stress Concentration in Tubular K-Joints with Diameter Ratio Equal to One", Steel in Marine Structures, Elsevier, Amsterdam, Netherlands, 1987, pp. 377-393.

[14] Dharmavasan, S. and Seneviratne, L.D., "Stress Analysis of POCHS K-Joints, Fatigue and Crack Growth in Offshore Structures”, IMechE, 1986-2, pp. 17-30.

[15] Lee, C.K., Lie, S.T., Chiew, S.P., Sopha, T. and Nguyen, T.B.N., “An Experimental Study on the Fatigue Behaviour of Partially Overlapped CHS K-Joints”, Proceeding of the $8^{\text {th }}$ International Conference on Steel Space Composite Structures, Kuala Lumpur, Malaysia, 2006, pp. 273-279.

[16] American Welding Society (AWS), “Structural Welding Code-Steel, ANSI/AWS D1.1-2000”, American Welding Society, Inc., Miami, 2000.

[17] Lee, C.K., Lie, S.T., Chiew, S.P. and Shao, Yongbo, "Numerical Models Verification of Cracked Tubular T, Y and K- Joints under Combined Loads", Engineering Fracture Mechanics, United States, 2005, Vol. 72, No. 7, pp 983 - 1009.

[18] Chiew, S.P., Lee, C.K., Lie, S.T., Nguyen, T.B.N. and Sopha, T., "Mesh Generation for Partially Overlapped Circular Hollow Section K-Joints under Fatigue Loadings”, The $2^{\text {nd }}$ International Maritime-Port Technology and Development Conference (MTEC 2007), 26-28 September 2007, Singapore. 